\author{
Aleksandra Maj \\ Uniwersytet Łódzki \\ a.maj@uni.lodz.pl
}

\title{
Koncepcja stu języków dziecka w przedszkolach Reggio Emilia. O przełamaniu hegemonii języka werbalnego w dziecięcym procesie uczenia się
}

\section{Summary \\ The Hundred Languages of Children in preschools in Reggio Emilia. Overcoming the hegemony of verbal language in children's learning process}

The paper presents the idea of the hundred languages of children interpreted by Reggio Emilia educators as "the different ways used by human beings to express themselves" (Vecchi 2010: 9). It also discusses the role of different languages (verbal, visual, mathematical, scientific language, etc.) in children's learning. By using various symbolic representations, children have the opportunities to show the same concept in different media. This process is described on the basis of short description of project conducted in Reggio Emilia preschools.

Słowa kluczowe: edukacja przedszkolna, Reggio Emilia, koncepcja stu języków dziecka, atelier

Keywords: preschool education, Reggio Emilia, the hundred languages of children, atelier

\section{Wprowadzenie}

Jednym z elementów wyróżniających podejście edukacyjne Reggio Emilia (dalej RE) ${ }^{1}$ jest idea stu języków dziecka, pielęgnowana w przedszkolach RE m.in. poprzez funkcjonowanie w każdej placówce atelier $^{2}$. Koncepcja ta jest owocem zmiany myślenia o dziecięcym

\footnotetext{
1 Szerzej podejście Reggio Emilia zostało opisane na łamach „Problemów Wczesnej Edukacji”: M. Karwowska-Struczyk (2011), Reggio Emilia - pożadana filozofia i praktyka dla edukacji przedszkolne, „Problemy Wczesnej Edukacji, 2(14); M. Szczepska-Pustkowska (2013), Sto języków dziecka: wczesna edukacja z inspiracji myśla pedagogiczna Lorisa Malaguzzi, „Problemy Wczesnej Edukacji, 1(20); J. Bonar, A. Maj (2015), Przedszkola Reggio Emilia we Włoszech miejscem rozkwitu dziecięcego potencjału, „Problemy Wczesnej Edukacji”, 4(31).

2 Atelier - przestrzeń zorganizowana na podobieństwo pracowni plastycznej, wyposażona jest w stoliki do pracy, sztalugi, komputer, drukarkę, sprzęt cyfrowy: kamerę, aparat fotograficzny, dyktafon, mikroskop oraz materiały wykorzystywane w trakcie realizacji projektów, jak glina, farby m.in. do ceramiki, różnokolorowe i o różnej grubości i fakturach papiery, druty, skrawki materiałów, folie, materiały naturalne: kasztany, liście, kamienie i in. Gospodarzem atelier jest atelierista, osoba z wykształceniem artystycz-
} 
procesie uczenia się i znaczeniu w tym procesie różnorodnych sposobów komunikacji. Jak wspominał L. Malaguzzi, wprowadzenie atelier dało dzieciom możliwość twórczego łączenia różnorodnych symbolicznych języków i ochroniło pedagogów RE przed behawiorystycznymi przekonaniami na temat otaczającej kultury, redukującymi ludzki umysł do roli naczynia do wypełnienia (Gandini 2012: 49-50). Dla nauczycieli RE, zainspirowanych myślami społecznych konstruktywistów, atelier $\mathrm{z}$ wpisaną $\mathrm{w}$ jego funkcjonowanie koncepcją stu języków dziecka stało się narzędziem odzyskiwania wizerunku dziecka silnego, kompetentnego, pełnego potencjału, dziecka, w którego procesie uczenia się niezwykłą rolę odgrywa bogactwo i różnorodność języków ekspresji.

\section{Dziecko jako posiadacz stu języków i uczestnik procesu komunikacji}

Według L. Malaguzziego, „dziecko rodzi się ze wszystkimi językami świata” (Filipini, Vecchi 2006: 30). Ponieważ posiada wrodzoną umiejętność komunikowania się, nie ma potrzeby uspołeczniania go, już od chwili narodzin jest bowiem istotą społeczną, zdolną nawiązywać relacje z innymi (Rinaldi 2006). Jak zaznacza L. Malaguzzi,

Interakcje z dorosłymi, z kulturą, z środowiskiem, z przedmiotami, cieniami, kolorami, przestrzenią, czasem, dźwiękami, zapachami i smakami sytuują dzieci bezpośrednio w świecie komunikacji i wymiany, świecie, z którego, selekcjonując i łącząc uczucia, emocje, odczucia [...], czerpią i otrzymują znaczenia, które stopniowo uczą się rozróżniać, organizować i przetwarzać. Świat przenika dzieci, tak jak dzieci przenikają świat (Cagliari i in. 2016: 374).

Dziecko, będąc aktywnym uczestnikiem świata komunikacji, jest zdolne tworzyć swoje własne symbole oraz odczytywać i rekonstruować te zastane (Rinaldi 2006). By wyrazić swoje pomysły, posługuje się różnymi środkami. Jak metaforycznie ujął to L. Malaguzzi: „Dziecko składa ze stu. Ma sto języków, sto rąk, sto myśli, sto sposobów na myślenie, bawienie się i mówienie" (Filipini, Vecchi 2006: 30). W podejściu RE język jest więc rozumiany znacznie szerzej niż tylko język werbalny. Claudia Guidici interpretuje języki następująco:

Kiedy mówimy o językach odnosimy się do różnorodnych sposobów przedstawiania, komunikowania i wyrażania przez dziecko (człowieka) swojego myślenia poprzez wykorzystanie różnych mediów i symbolicznych systemów; dlatego też języki to wielość czcionek i źródeł wiedzy (Vecchi 2010: 9).

Bogate i kompetentne dziecko, posługując się różnorodnymi i nieograniczonymi symbolicznymi reprezentacjami, wykorzystuje w trakcie uczenia się słowa, ruch, rysunek, dramę czy muzykę. Liczba sto ma tutaj charakter symboliczny, z jednej strony oznacza wielość i różnorodność języków (język wizualny, język matematyczny, język naukowy

nym, której zadaniem jest pomaganie nauczycielom dostrzec ekspresyjne właściwości każdego z języków i jak najpełniej wykorzystać potencjał każdego z nich. 
itd.), z drugiej zaś podkreśla równy status każdego z nich. Będąc ,antidotum na standaryzację komunikacji i jednorodność" (Gandini 2015: 71), sprzyja dziecięcej indywidualności i dziecięcej potrzebie wyrażania pomysłów w interdyscyplinarnej formie. V. Vecchi (2010) konstatuje:

Gdy w pedagogice Reggio deklarujemy, że dziecko posiada sto języków i posługuje się stoma językami,[...] hipotetyzujemy, że zachodzi proces uczenia się, w trakcie którego kilka języków (dyscyplin) wchodzi w interakcję ze sobą (tamże: 18).

Celem edukatorów RE nie jest rozwiązanie problemów z perspektywy jednej dyscypliny naukowej, ale eksplorowanie i dociekanie z wykorzystaniem transdyscyplinarnego nawozu, petnego wartości odżywczych jak nazywa koncepcję stu języków dziecka V. Vecchi (tamże). Każdy z języków niesie ze sobą potencjał, który pozwala na zbadanie tematu głębiej i wnikliwiej, a wielość i różnorodność sposobów komunikacji sprzyja dialogowi pomiędzy pojęciami oraz sposobami myślenia dzieci i dorosłych.

\section{Różnorodność języków dziecka i ich właściwości}

Każde medium jest odrębnym językiem (Forman 1994), posiadającym swój własny alfabet, który odnosi się nie tylko do właściwości fizycznych, ale również do sposobu, w jaki dane medium można przekształcać. Giovanni Piazza w wywiadzie z Lellą Gandini definiuje alfabet jako ,[...] kombinację cech charakterystycznych danego materiału wraz z relacją, która wyłania się podczas interakcji z nim" (Gandini 2005: 13). Poszczególne media posiadają odmienne afordancje (affordances) $)^{3}$, które sprawiają, że niektóre koncepcje dają się przedstawić łatwiej od innych. George Forman postrzega afordancje jako „możliwość transformacji medium, której dziecko z łatwością może dokonać” oraz jako „relację pomiędzy podlegającymi transformacjom właściwościami medium a dziecięcą potrzebą wykorzystania tych właściwości w celu tworzenia symboli” (Forman 1994: 38). Oznacza to, że potencjał danego medium ujawnia się trakcie jego przekształcania, a afordancje sugerują możliwe działania oraz różne sposoby wykorzystania medium w celu przedstawienia swoich pomysłów czy interpretacji. Materiały stają się narzędziem ekspresji, wspierającym komunikację. G. Forman (1994) wyróżnił kilka cech mediów, które

\footnotetext{
3 Termin affordances ukuł amerykański psycholog percepcji J.J. Gibson, według którego określane są one jako możliwości działania, na jakie pozwalają dane obiekty bądź środowisko dla wchodzącego z nimi w interakcje agenta (człowieka lub zwierzę) (Lubiszewski 2012). W kontekście moich rozważań bardziej adekwatna wydaje się być definicja wprowadzona przez Dona Normana, według którego afordancje oznaczają własności przedmiotów i osób oraz relację pomiędzy przedmiotem i osobą. Afordancje odnoszą do tego, co z danym przedmiotem można zrobić, nie ograniczając się tylko i wyłącznie do bezpośredniej funkcji przedmiotu (zob. video: Don Norman explains affordances https://www.youtube.com/wat$\mathrm{ch}$ ? $\mathrm{v}=\mathrm{NK} 1 \mathrm{Zb}$ 5VxuM, 9.03.2017). Ze względu na trudności translacyjne zdecydowałam się na użycie spolszczonej nazwy afordancje. W polskiej literaturze pojawiały się też tłumaczenie „dostarczanty” lub „oferty”, użycie ich w niniejszym tekście mogłoby być jednak niezrozumiałe.
} 
W większym stopniu niż kolor czy kształt wpływają na ich potencjał reprezentacji. Należą do nich: modułowość (modularity), trwałość w czasie (the persistence across time) oraz reagowanie na zmiany (media that react to changes). $\mathrm{Z}$ perspektywy opisanego poniżej epizodu dziecięcego uczenia się trzecia cecha jest najistotniejsza. Odnosi się ona do zakresu informacji zwrotnej dostarczanej przez medium. Jedne media są mediami pasywnymi (non-reactive media) i nie dają możliwości weryfikację pomysłów, inne zaś to media aktywne (reactive media), posiadające funkcję autokorekcji. Wykorzystując graficzne reprezentacje, dziecko może narysować każdą budowlę, nawet taką, której ze względu na prawa fizyki w rzeczywistości nie udałoby się zbudować. Dopiero wykorzystanie prawdziwych klocków stwarza dzieciom możliwość weryfikacji swojego pomysłu (Forman (1994).

Posługiwanie się wieloma językami wzbogaca dziecięcy proces uczenia, dlatego też niezwykle ważne jest budowanie dziecięcej wiedzy na temat poszczególnych języków, ich właściwości oraz możliwości ich wykorzystania w celu przedstawienia swoich własnych interpretacji rzeczywistości.

\section{Synergia pomiędzy językami i ich znaczenie w pracy metodą projektów}

Bogactwo języków komunikacji i ich jednakowy status daje dzieciom szansę na wyrażenie swoich pomysłów w najbardziej komfortowy dla nich samych i najbardziej czytelny dla innych sposób. Współistnienie i współdziałanie różnorodnych języków doprowadza do głębszego i bardziej wnikliwego rozumienia badanego tematu. Ponieważ języki wcho-

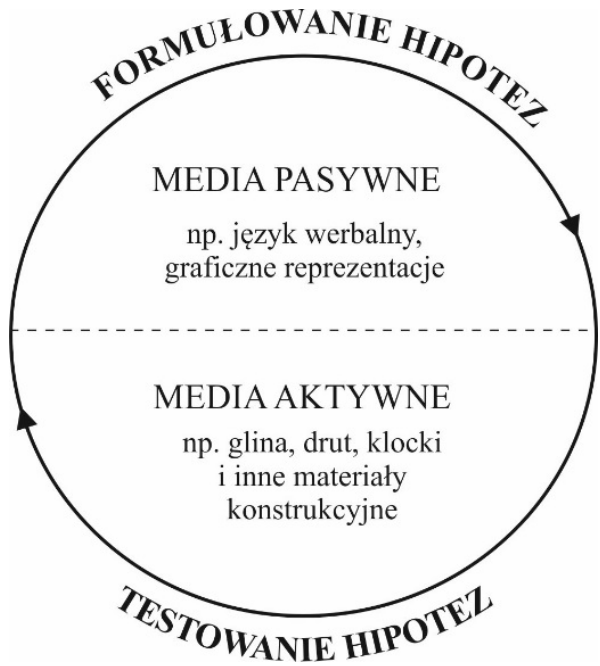

Model 1. Dziecięcy proces uczenia się z wykorzystaniem różnorodnych języków

Źródło: opracowanie własne. dzą w interakcje ze sobą i oddziałują na siebie, dochodzi do zjawiska synergii. Odgrywa ono istotną rolę w pracy metodą projektów, która w podejściu RE określana jest mianem progettazione (zob. Maj 2014). W strategii tej dziecięca aktywność nie jest wynikiem $\mathrm{z}$ góry zaplanowanych działań, ale wyłania się w toku wspólnej (dzieci i dorosłych) pracy. Realizując projekt, dzieci mają okazję do stawiania hipotez i weryfikowania ich. Szczególną rolę w procesie tym pełnią różne języki, które ze względu na swoje właściwości dysponują potencjałem możliwym do wykorzystania na różnych etapach projektów. Jedne z języków są bardziej odpowiednie do formułowania hipotez, inne zaś do ich testowania (Forman 1994). Zależność tę ilustruje model 1 . 
Formułowanie hipotez. Znaczenie dyskusji i graficznych reprezentacji

Na początkowym etapie projektu, w trakcie którego rozwijany jest pomysł na jego realizację, dzieci stawiają hipotezy, formułując swoje pierwsze teorie odnośnie do badanego zjawiska. $\mathrm{Na}$ etapie tym dominują język werbalny oraz graficzne reprezentacje. Jako media pasywne (nieograniczone prawami fizyki, bez właściwości autokorekcji) umożliwiają dzieciom swobodę w myśleniu i dają możliwość generowania niezliczonych pomysłów, do czasu wyłonienia się rozsądnej dla nich hipotezy (Forman 1994). Poprzez dostęp do zakorzenionych w słowach i frazach wspomnieniach język werbalny uaktywnia proces przywoływaniu swoich wcześniejszych doświadczeń (revisiting) (Forman 2005). Jest narzędziem umożliwiającym fantazjowanie, pozwala dzieciom na intuicyjnie działanie i tworzenie nawet takich projektów, które pomimo że brzmią sensownie i logicznie, w rzeczywistości nigdy nie mogłyby zaistnieć. Dla G. Formana (1994) język werbalny jest ,placem zabaw pomysłów bez powściągania ich przez uniwersalne prawa fizyki” (Forman 1994: 40).

Podczas dyskusji w projekcie wyłania się wiele nowych hipotez, dzieci dochodzą jednak do momentu, w którym przedstawione za pomocą języka mówionego pomysły wymagają bardziej szczegółowego wyjaśnienia. Ilustrowane są one wówczas za pomocą graficznych reprezentacji. Wynika to z potrzeby jasności i czytelności, a rysunek, co podkreślał L. Malaguzzi, jest narzędziem komunikacji prostszym i bardziej czytelnym niż słowa (Gandini 2012). Reprezentacje graficzne mają charakter otwarty, umożliwiają tworzenie różnych, czasem niezgodnych ze światem rzeczywistym, projektów. Choć, jak zauważa G. Forman (1994), stanowią dla dziecka wyzwanie poznawcze (dziecko musi wymyśleć kształty i linie, które nie są zawarte w medium, odczytać znaki jako odpowiednik rzeczywistych przedmiotów, podlegających prawom fizyki), są narzędziem najlepszym do projektowania.

\section{Testowanie hipotez}

Kolejnym krokiem w metodzie projektów jest testowanie hipotez. Weryfikowanie dziecięcych teorii odbywa się poprzez wykorzystanie symbolicznych języków, które mają charakter aktywny (np. materiałów konstrukcyjnych). Dzięki nim dzieci umiejscawiają swoje obrazy w funkcjonalnym kontekście. Glinę, drut, karton i inne trójwymiarowe media charakteryzuje spontaniczna reakcja na prawa fizyki. Korzystając z nich, dzieci przeprowadzają symulacje, które pozwalają na weryfikację wcześniej postawionych hipotez.

Jednym z języków, który cechuje niezwykła elastyczność, jest język cyfrowy. Rozwój technologii przyczynił się do wprowadzenia w przedszkolu nowoczesnych technologii (komputery, cyfrowe kamery, dyktafony). O jej zaletach pisał G. Piazza (2007):

Technologia ta daje okazję uczestniczenia w obrazach, zagłębiania się w nie, zarówno w skali mikro, jak i makro, przenoszenia punktów widzenia i przeglądania różnych obrazów w tym samym czasie, doświadczania wymyślonej rzeczywistości oraz zanurzania się w niewystępujących w naturze efektach świetlnych, a także umożliwia transformację dźwięków w trakcie ich tworzenia (Piazza 2007: 119). 
Medium cyfrowe, które odnosi się do każdego rodzaju plików zapisanych na dysku komputera (Forman 2012), stwarza niespotykane dotąd możliwości transformacji, które pozwalają na testowanie dziecięcych teorii. Media te, będąc komplementarnymi wobec pozostałych języków, uzupełniają je, dając szansę na uwidocznienie nieuchwytnych przez inne języki aspektów tego samego zjawiska.

Doświadczenie dziecięcego uczenia się z wykorzystaniem różnorodnych języków

Opisywany epizod jest fragmentem długoterminowego projektu „Wesołe miasteczko dla ptaków", realizowanego przez kilka miesięcy w przedszkolu La Viletta ${ }^{4}$. W wyniku przedszkolnych dyskusji i negocjacji dzieci postanowiły zbudować wesołe miasteczko dla ptaków odwiedzającego ich przedszkolny ogród. Jednym z jego elementów miało być koło wodne, a przedstawiony poniżej fragment jest ilustracją wykorzystania różnorodnych mediów w celu jego reprezentacji.

Filippo, jeden z chłopców narysował góry z dwoma tunelami, z których spływająca woda poruszała kołem wodnym oraz koło wodne, którego łopatki służyły nurkującym ptakom za trampolinę (rys. 1).

Filippo: Aby topatki się poruszały, trzeba z góry puścić strumień wody, tak jak wodospad. Na moim rysunku narysowatem jeden prawdziwy kanat, i drugi, który jak nie ma wody, bierze ja z gór i sprawia, że topatki się poruszaja, ptaki moga się bawić (Filipini, Vecchi 2006: 136).

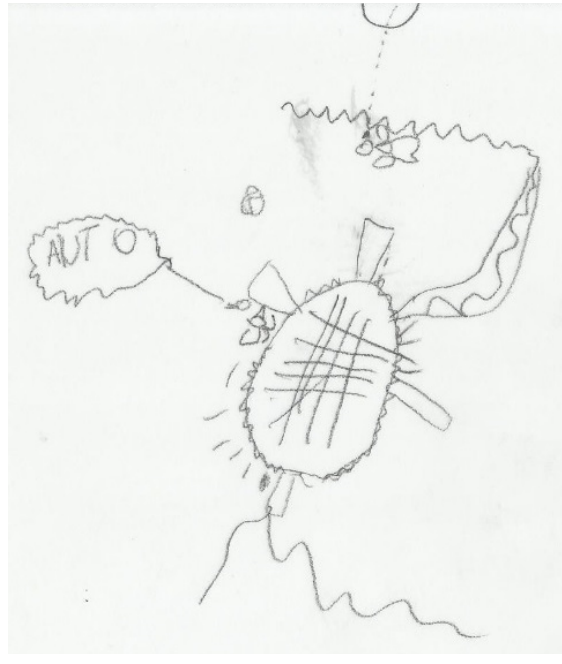

Rysunek 1. Rysunek koła wodnego Filippo Przerysowany za Forman, Gandini 1994
Następnie, na podstawie rysunku Filippo przygotował papierowy model koła wodnego (rys. 2). Ponieważ na rysunku nie uwzględnił właściwego położenia łopatek, umożliwiającego nabieranie wody i poruszanie się koła pod jej naporem, ten sam błąd popełnił tworząc papierowy model, a następnie, wzorując się na nim, model z gliny (rys. 3).

Podobne doświadczenia miał kolega Filippo - Andrea. Andrea również narysował łopatki koła wodnego w pozycji frontalnej (rys. 4) i ponieważ użył swojego rysunku jako wskazówki dla stworzenia papierowego modelu, umieścił łopatki w takiej samej, błędnej pozycji (rys. 5). Nauczycielka postanowiła nie interweniować, ponieważ z założenia transfer z jednego języka na drugi daje dzieciom szansę na testowanie swoich hipotez i zweryfikowanie dotychczasowej wiedzy.

4 Szerszy opis tego projektu można znaleźć w Maj 2014. 


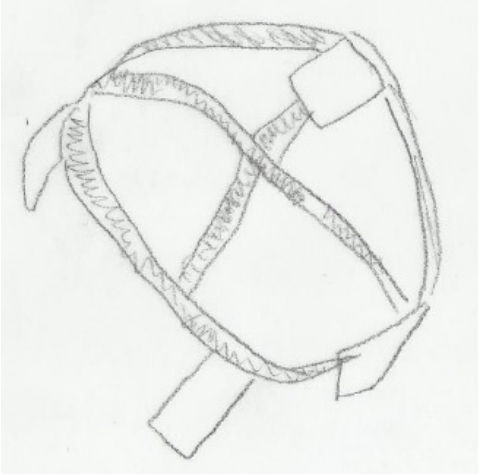

Rysunek 2. Szkic papierowego modelu Filippo

Przerysowany za Forman, Gandini 1994

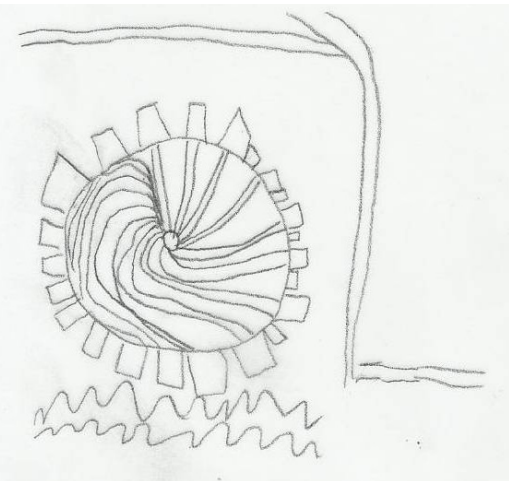

Rysunek 4. Rysunek koła wodnego Andrei Przerysowany za Filipini, Vecchi, 2006: 137

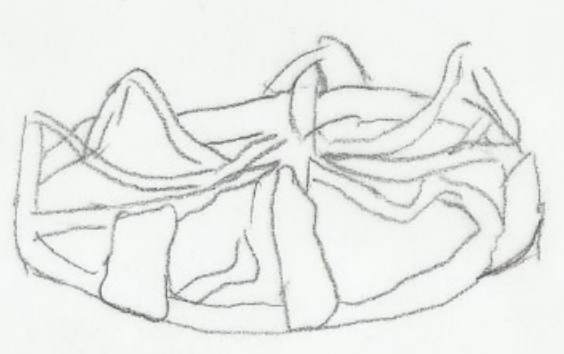

Rysunek 3. Szkic modelu z gliny Filippo Przerysowany za Forman, Gandini 1994

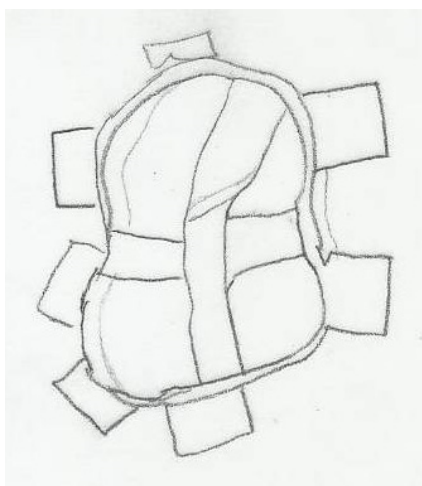

Rysunek 5. Model papierowy koła wodnego Andrei

Przerysowany za Filipini, Vecchi, 2006: 137

Andrea postanowił zbudować też model z gliny. Dostrzegł błąd i dokonał korekty swojego projektu.

Andrea: Wiesz, Amelia, co razem z Filippo sobie pomyśleliśmy, i wiesz, że łopatki jak te... woda nie jest wystarczajaco silna dla topatek i koło się zatrzymuje. Próbowaliśmy woda z kranu. Musimy zmienić położenie topatek (Filipini, Vecchi, 2006: 137).

G. Forman (1994) tworząc dokumentację z projektu i dokonując interpretacji pracy Andrei, zwrócił uwagę, że odmienne afordancje kartonu i gliny (glina jest materiałem, który cechuje zmienność, łatwość modyfikacji, natomiast obiekt wykonany z papieru, sklejony i zszyty, jest trwały i niepodatny na zmiany i transformacje) mogły mieć wpływ na korektę 
myślenia chłopca. Być może koło wodne wykonane z gliny było uważniej niż model z kartonu odczytywane jako przedmiot, o który może rozbić się woda aniżeli model z papieru. Być może wyobrażenie wody uderzającej o gliniany panel zainspirowało do refleksji na temat ułożenia dwóch płaszczyzn: powierzchni wody i łopatki koła (Forman 1994).

Dzięki przedstawianiu swojego pomysłu za pomocą różnych materiałów dzieci miały okazję do zwrócenia uwagi na odmienne aspekty problemu i tym samym dostrzeżenie błędu w swoim myśleniu. Konieczność korekty pozycji łopatek doprowadziła do eksperymentowania z innymi materiałami. Powstały koła wodne, w których jako łopatki wykorzystano aluminiowe pojemniki (rys. 6) czy plastikowe kubki i łyżeczki (rys. 7). Filippo wraz ze swoimi kolegami testował swoje koło wodne w specjalnie zbudowanym pojemniku z wodą, co ostatecznie pozwoliło na zrozumienie zasady jego działania i konieczności ułożenia łopatek w odpowiedniej pozycji.

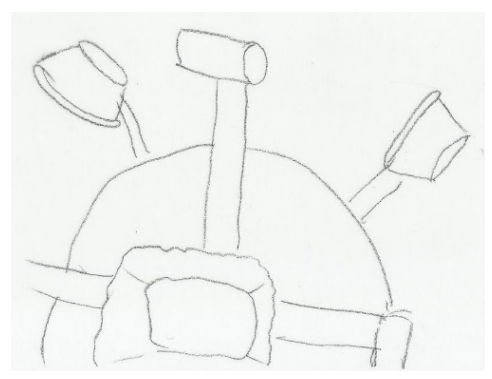

Rysunek 6. Model Filippo

Przerysowany za Forman, Gandini 1994

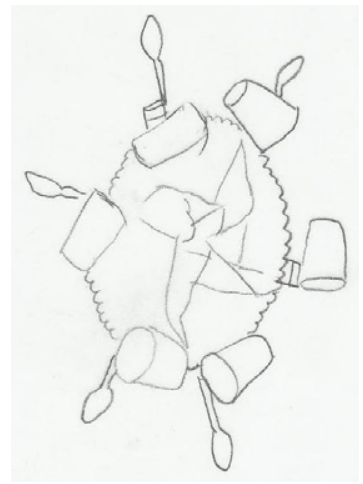

Rysunek 7. Model Elisy

Przerysowany za Filipini, Vecchi, 2006: 137

Opisane powyżej doświadczenie jest przykładem stopniowego przenoszenia wiedzy dziecka z jednej symbolicznej reprezentacji na drugą, dzięki któremu następuje weryfikacja dziecięcych hipotez 5 .

\section{Zakończenie}

Koncepcja stu języków dziecka przyjęta przez edukatorów Reggio, uznająca znaczenie i równy status każdego z języków, przełamuje dominującą pozycję języka werbalnego w dziecięcym procesie uczenia się. Choć bez wątpienia język ten odgrywa bardzo ważną rolę, to wiedza uzyskana dzięki integracji języków staje się bardziej rozbudowana. Dzieci,

\footnotetext{
5 Proces weryfikacji dziecięcych hipotez został również opisany na stronie harvardzkiego Projektu Zero http:/www.pz.harvard.edu/sites/default/files/Making\%20Learning\%20Visible_\%20Ring-Around-The-Rosie\%20Documentation.pdf, 10.03.2017.
} 
przekładając jeden kod na drugi i wykorzystując odmienne właściwości mediów, dokonują transformacji, dzięki której dostrzegają nowe aspekty problemu. W trakcie transferu z jednego języka na drugi selekcjonują pomysły i eliminują te zbędne, zbyt ogólne oraz dokonują, co w procesie uczenia się jest niezwykle ważne, weryfikacji wcześniej postawionych hipotez. Ponieważ wykorzystanie różnorodnych języków wzbogaca dziecięcy proces uczenia się, warto dawać dzieciom szansę na zaprezentowania swojej wiedzy nie tylko za pomocą słów.

\section{Literatura}

Cagliari P., Castagnetti M., Giudici C., Rinaldi C., Vecchi V., Moss P. (red.) (2016), Loris Malaguzzi and the Schools of Reggio Emilia. A selection of his writings and speeches, 1945-1993. London, Routledge.

Filipini T., Vecchi V. (red.) (2006), The Hundred Languages of Children. Reggio Emilia, Reggio Children S.r.1.

Forman G. (1994), Different Media, Different Languages. W: L. Katz, B. Cesarone (red.), Reflections on the Reggio Emilia Approach. Urbana, ERIC Clearinghouse on Elementaryand Early Childhood Education.

Forman G. (2005), The Project Approach in Reggio Emilia. W: C.T. Fosnot (red.), Constructivism:Theory, Perspectives, and Practice. New York, Teachers College Press.

Forman G. (2012), The Use of Digital Media in Reggio Emilia. W: C. Edwards, G. Forman, L. Gandini (red.), The Hundred Languages of Children. The Reggio Emilia Experience in Transformation. Santa Barbara, Praeger.

Forman G., Gandini L. (1994), The amusement park for birds [kaseta VIDEO], Performanetics, 19 The Hollow, Amherst, MA01002.

Gandini L. (2005), From the Beginning of the Atelier to Materials as Languages. Conversations from Reggio Emilia. W: Gandini L., Hill L., Cadwell L., Schwall Ch. (red.), In the Spirit of Studio. Learning from the Atelier of Reggio Emilia. New York, Teacher Collage Press.

Gandini L. (2012), History, Ideas, and Basic Principles: An Interview with Loris Malaguzzi. W: C. Edwards, G. Forman, L. Gandini (red.), The Hundred Languages of Children. The Reggio Emilia Experience in Transformation. Santa Barbara, Praeger.

Lubiszewski D. (2012), Odnaleźć się w gąszczu ofert. Psychologia ekologiczna dla bardzo poczatkujacych. http://avant.edu.pl/wp-content/uploads/DL-Odnalezc-sie-w-gaszczu-ofert.pdf, 09.03.2017.

Maj A. (2014), Metoda projektów we wczesnej edukacji szansq demokratyzacji przestrzeni edukacyjnej dziecka. W: K. Gawlicz, P. Rudnicki, M. Starnawski, T. Tokarz (red.), Demokracja i edukacja: dylematy, diagnozy, doświadczenia. Wrocław, Wydawnictwo Naukowe Dolnośląskiej Szkoły Wyższej.

Piazza G. (2007), On the wave of creativity: Children, expressive languages and technology. "International Journal of Education through Art" 2 (3).

Rinaldi C. (2006), In Dialogue with Reggio Emilia. Listening, Researching and Learning. London, Routledge.

Vecchi V. (2010), Art and Creativity in Reggio Emilia. London, Routledge. 